\begin{tabular}{|c|c|}
\hline $\begin{array}{l}\text { 2. To: (Receiving organization) } \\
\text { Distribution }\end{array}$ & $\begin{array}{l}\text { 3. From: coriginating organization) } \\
\text { Authorization Basis } \\
\text { Management \& Implementation }\end{array}$ \\
\hline $\begin{array}{l}\text { 5. Proj./Prog./Dept./Div.: } \\
\text { Org. Code }-2 \text { N150 }\end{array}$ & $\begin{array}{l}\text { 6. Design Authority/ Design Agent/Cog. } \\
\text { Engr.: } \\
\text { D. P. Mendoza }\end{array}$ \\
\hline
\end{tabular}

8. originator Remarks:

This EDT transmits the Tank Waste Remediation System (TWRS) Authorization Basis (AB) Configuration Control Summary. The purpose of this document is to outline the processes and tools to be used for configuration control of the TWRS AB.

11. Receiver Renarks:

N/A
11A. Design Baseline Document? [] Yes [X] No
4. Related EDT No.:
N/A
7. Purchase Order No.:
N/A

9. Equip./Component No.:

$\mathrm{N} / \mathrm{A}$

10. System/Bldg./Facility:

N/A

12. Major Assm. Dwg. No.:

N/A

13. Pernit t/Permit Application No.: $N / A$

14. Required Response Date:

December 19,1997

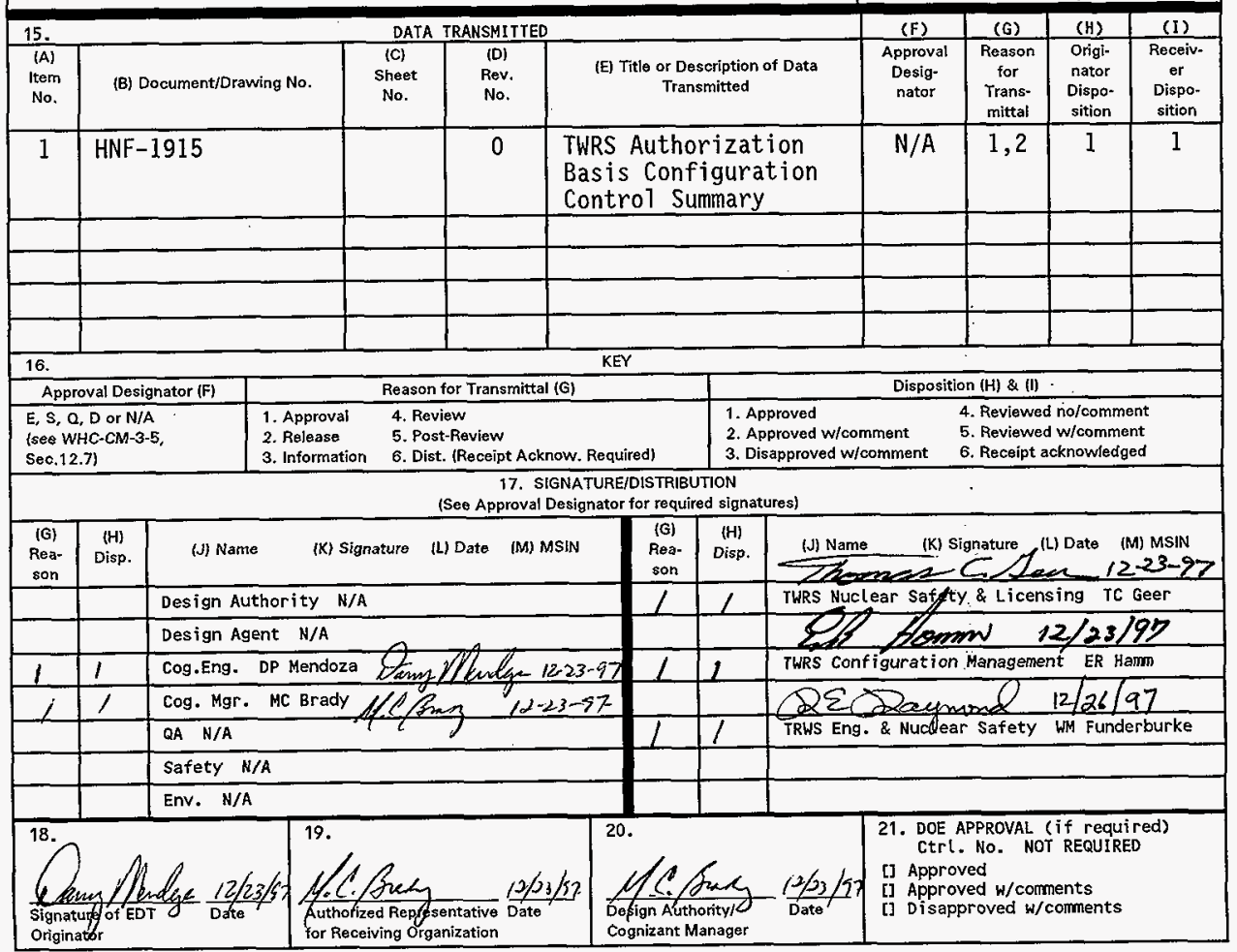




\section{TWRS Authorization Basis Configuration Control Summary}

D. P. Mendoza

Duke Engineering \& Services, P. 0. Box 350, Richland, WA 99352

U.S. Department of Energy Contract DE-AC06-96RL13200
EDT/ECN: 623766
Org Code: 2N150
UC: 2030
Charge Code: NF52A
B\&R Code: EW3120071
Total Pages: 23

Key Words: Configuration Control, Authorization Basis, Configuration Management, Unreviewed Safety Question, Authorization Basis Amendments

Abstract: This document was developed to define the Authorization Basis management functional requirements for configuration control, to evaluate the management control systems currently in place, and identify any additional controls that may be required until the TWRS

Configuration Management system is fully in place.

TRADEMARK DISCLAIMER. Reference herein to any specific comercial product, process, or service by trade name, trademark, manufacturer, or otherwise, does not necessarily constitute or imply its endorsement, recommendation, or favoring by the United States Government or any agency thereof or its contractors or subcontractors.

Printed in the United States of America. To obtain copies of this document, contact: Document Control Services, P.0. Box 950, Mailstop H6-08, Richland WA 99352, Phone (509) 372-2420; Fax (509) 376-4989.
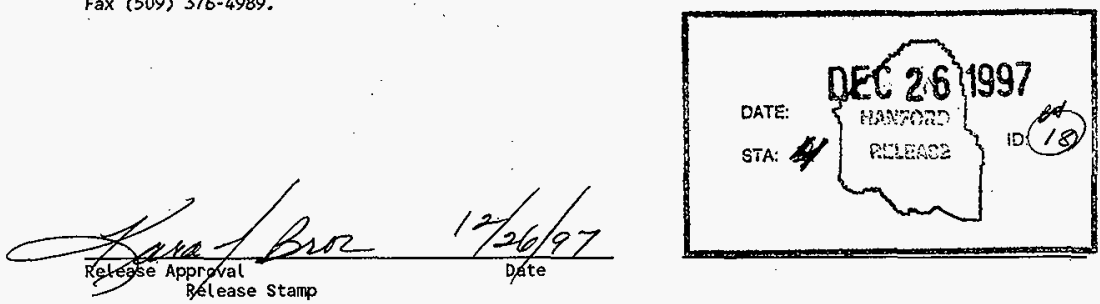
HNF-1915, Rev 0

TWRS AUTHORIZATION BASIS

CONFIGURATION CONTROL SUMMARY 
HNF-1915, Rev 0

\section{EXECUTIVE SUMMARY}

The U. S. Department of Energy, Richland Operations Office (RL) has identified in a management assessment the need to clarify the controls used for the configuration management of the Tank Waste Remediation System (TWRS) Authorization Basis. This document specifically addresses Finding 18a of the RL management asșessment.

Configuration Management of the Authorization Basis (AB) and its approved changes is required to maintain the $A B$ baseline. This document was developed to define the Authorization Basis Configuration Management functional requirements, to identify the management control systems currently in $\mathrm{place}$, and identify any additional controls that may be required until the TWRS Configuration Management Plan is strengthened.

Evaluation of the existing process used for the management of the authorization basis concluded that the applicable elements of configuration management are in place for the effective management of the TWRS Authorization Basis. 
EXECUTIVE SUMMARY .................. $\ldots \ldots$ i

TABLE OF CONTENTS ...........................

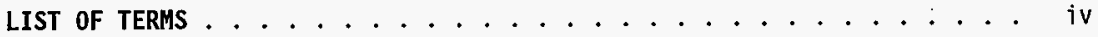

1.0 INTRODUCTION ...................... 1

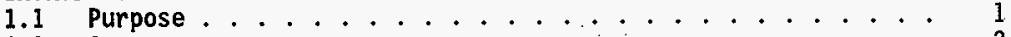

1.2 scope .......................... 2

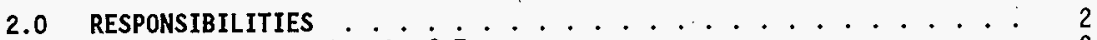

2.1 U. S. Department of Energy .............. 2

2.2 Fluor Daniel Hanford ................ 2

2.3 THRS Engineering \& Nuciear Safety ............ 2

2.4 TWRS Configuration Management Program .......... 3

2.5 Nuclear Safety \& Licensing ............. 3

2.6 P1 ant Review Committee ............. 3

$3.0^{\circ}$ CONFIGURATION MANAGEMENT SYSTEM REQUIREMENTS ......... 3

3.1 CM Item Identification . . . . . . . . . . . . . 4

3.2 Configuration Status Accounting . . . . . . . . . . . 4

3.3 Change Control ................ 4

3.4 Configuration Management Program Assessment . . . . . . . . 6

4.0 EXISTING CONTROLS AND PROCEDURES ............ 6

4.1 CM Item Identification (Basei ine Identification) $\ldots \ldots$

4.2 Configuration Status Accounting ............ 7

4.3 Change Control ................ 7

4.3.1 Evaluation of Change to AB . . . . . . . . 7

4.3.2 Authorization Basis Amendment and Approval . . . . 8

4.3.4 AB Update and Approval ............. . 9

4.3.5 Document Maintenance . . . . . . . . . . . . 9

4.4 Supporting Activities and Interfaces .......... 10

4.5 Configuration Management Program Assessments ........ 11

4.6 Management of Defense-in-Depth Features ......... 11

5.0 CONCLUSION AND RECOMMENDATIONS .................... 11

6.0 REFERENCES ............................ 15

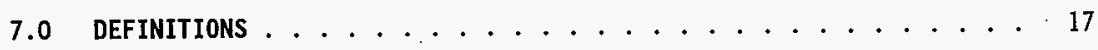

\section{FIGURES}

Figure 1 - TWRS Configuration Management Process ......... 5

TABLES

Table 1 - Topical Section References \& Implementing Procedures . . . . 13 


\section{LIST OF TERMS}

$A B$

ARMI

BIO

CM

CMIP

CMP

DID

ECN

FDH

ISMS

JCO

MA

MOU

NS\&L

PIAB

PHMC

PRC

RA

$\mathrm{RL}$

SSC

TIMS

TSR

TWRS

USQ
Authorization Basis

Authorization Basis Requirements Management Interface

Basis for Interim operation

Configuration Management

Configuration Management Implementation Plan

Configuration Management Plan

Defense-In-Depth

Engineering Change Notice

Fluor Daniel Hanford

Integrated Safety Management System

Justification for Continued Operation

Management Assessment

Memorandum of Understanding

Nuclear Safety \& Licensing

Potential Inadequacy in the Authorization Basis

Project Hanford Management Contractor

Plant Review Committee

Readiness Assessment

U. S. Department of Energy, Richland Operations Office Structure, System, and Component

Training Information Management System

Technical Safety Requirement

Tank Waste Remediation System

Unreviewed Safety Question 
HNF-1915, Rev 0

\subsection{INTRODUCTION}

Documents describing aspects of the facility design basis and operational requirements relied upon by the U. S. Department of Energy, Richland Operations office (RL), to authorize operations are designated as the Authorization Basis (AB) documents. These descriptions (equipment, requirements, assumptions, etc.) in the $A B$ are essential to the safety of facility operations. Maintaining the $A B$ documents under Configuration Management is one element of the TWRS integrated safety management system (ISMS) which ensures the consistency, formality, and rigor essential to safety management.

The Tank Waste Remediation System (TWRS) has an established, RL approved list of $A B$ documents and controls (Wagoner 1997), which includes the TWRS Basis for Interim Operation (BIO), and its associated Technical Safety Requirements (TSRs). This complete set of documents comprising the TWRS $A B$ defines the safety envelope (i.e., the risk) that RL has determined to be acceptable for TWRS operation. The TWRS $A B$ baseline is made up of this set of documents plus or minus any approved changes. It is essential that the $A B$ baseline be maintained under a Configuration Management Program.

The Hanford Site Configuration Management System (CM) as described in HNF-MP-013, Configuration Management PJan, was used as the reference for the development of this document. The TWRS $A B$ configuration management activities and implementation will integrate with the TWRS Configuration Management Plan (CMP) and the TWRS Configuration Management Implementation Plan (CMIP) when revised. This document follows the general outline of HNF-MP-013 with emphasis on requirements for $C M$ of the TWRS $A B$.

\subsection{Purpose}

The purpose of this document is to identify the configuration management process required to maintain the TWRS $A B$ documents and to identify the existing procedures and controls that implement this process. Identification of the CM process will improve the degree of confidence in the management of the TWRS $A B$ and its data, and improve the availability of the $A B$ data and information.

This document specifically addresses Finding 18a identified by the DOE/RL TWRS Management Assessment (MA), documented in U.S. Department of Energy, Richland Operations Office, Tank Waste Remediation System Management Assessment - Volume I, Determination of Readiness to Implement Tank Waste Remediation Basis for Interim Operations, DOE/RL-97-72, Rev. 0. This finding specifically stated, "Configuration Management was the most prevalent issue raised during the $M A$ and Readiness Assessment (RA) reviews. The $M A$ is in agreement with the statement in the RA report that the change control process does not assure timely plant management review of modifications to the implementation of defense-in-depth features, or other similar requirements in the BIO. The current change control processes do not ensure that changes to plant processes or controls which affect defense-in-depth features, assumptions or commitments in the BIO will receive an appropriate level of review and approval within the operating contractor or within the integrating contractor." 


\subsection{Scope}

Finding $18 \mathrm{a}$ identified by the DOE/RL. TWRS MA referenced defense-in-depth (DID) features which are existing engineered features or administrative programs or procedures that may further reduce the risk of an accident, but are not essential requirements like safety structures, systems, and components and TSR controls. Chapter 4.0 of the BIO specifically identifies the following disciplines to be DID systems and components: existing configuration management processes, approved work authorization and work control processes, management oversight and assessment programs, quality assurance processes and procedures, and training on approved written procedures.

This document addresses the CM implementation activities associated with the management and maintenance of the TWRS $A B$ baseline (including quality assurance, training, procedures, etc.) to assure that changes are controlled, tracked, archived, completed, and implemented. Only the control of $A B$ information and data is addressed by this document.

Configuration Management of TWRS hardware and equipment items (both safety SSCs and DID SSCs) are documented in HNF-SD-WM-SEL-040, TWRS Facility Safety Equipment List, and will be outlined in the TWRS CMP and the CMIP and addressed by those organizations that operate and maintain these items. They are therefore excluded from the scope of this document.

\subsection{RESPONSIBILITIES}

This section identifies the roles and responsibilities specific to TWRS $A B C M$ process. Roles and responsibilities specific to the processes described in this document are outlined in the respective implementing procedures identified in Table 1 .

\subsection{U. S. Department of Energy}

RL has the sole responsibility for evaluating and approving the $A B$. RL has committed to developing and establishing the requirements and appropriate implementing procedures that address the creation and maintenance of an $A B$ docket system. This system will be used to prioritize and schedule RL Tier II and Tier III reviews of proposed $A B$ changes.

\subsection{Fluor Daniel Hanford}

Fluor Daniel Hanford (FDH) is responsible for developing and establishing overal1. requirements and implementing procedures that address $\mathrm{CM}$ management responsibilities and methodologies. $\mathrm{FDH}$ is also responsible for the direct interface between RL (letters of direction, etc.) and TWRS subcontractors.

\subsection{TWRS Engineering \& Nuclear Safety}

TWRS Engineering \& Nuclear Safety is responsible for directing tasks relative to the development and maintenance of the TWRS Configuration Management Plan which provides the framework for system level $C M$ of the $A B$. 


\subsection{TWRS Configuration Management Program}

The TWRS Configuration Management Program manager has the overall responsibility for the development, management, and implementation of the TWRS Configuration Management Program. Responsibilities also include responding to configuration management related assessments and evaluation findings, and assuring integration with FDH configuration management requirements.

\subsection{Nuclear Safety \& Licensing}

TWRS Nuclear Safety \& Licensing (NS\&L) has the overall responsibility for maintaining and implementing the TWRS $A B$ Configuration Management process. This includes the following responsibilities:

- Develops, delivers, and maintains the authorization basis documents for TWRS facilities including supporting safety analyses and attendant

Technical Safety Requirements.

- Develops, implements, and maintains a system for managing safety documentation.

- Maintains an Unreviewed Safety Question (USQ) process.

In addition, the NS\&L manager has the responsibility to assure that all. proposed changes to the $A B$ are formally communicated to $R L$ for inclusion on the RL docket.

\subsection{Plant Review Committee}

The Plant Review Committee (PRC) is composed of personnel appointed by the Vice President, Tank Waste Operations. The PRC has ultimate contractor authority and responsibility for the management of the TWRS AB. Specific responsibilities include:

- Evaluation against the TWRS $A B$ of any issues submitted to the Plant Review Committee.

- Evaluation of issues concerning the identification and resolution of unreviewed safety questions, justifications for continued operation, and other matters relating to Tank Waste Operations.

- Interpretation of the intent of technical safety requirements and transitional requirements (Operational Safety Requirements and Interim Operational Safety Requirements) and other matters relating to the safe operation of the TWRS facilities.

\subsection{CONFIGURATION MANAGEMENT SYSTEM REQUIREMENTS}

HNF-MP-013, Configuration Management Plan, was reviewed as part of the development process for this document. The applicable elements defined in HNF-MP-013 that apply to the CM of the TWRS $A B$ are CM item identification, configuration status accounting, change control, and configuration management program assessments. 
The TWRS $A B C M$ process is shown in Figure 1, TWRS $A B$ Configuration Management Processes. This figure identifies the sub-processes required to manage the $A B$ baseline, and identifies the boundaries of responsibility for $A B$ configuration management, the interfaces with other processes, and related sub-processes. Also shown in Figure 1 are the process flows, and the process input/outputs.

\subsection{Item Identification}

CM item identification is required in order to establish a baseline that will be managed under $C M$. This requires identification of the information and the responsibilities for the control of $A B$ portion of the technical baseline. The $A B$ baseline consists of the current RL approved $A B$ documents, plus any approved changes to the $A B$. $A B$ baseline management functions include the identification of change initiators, implementation of a change control process, and establishing implementation interfaces.

\subsection{Configuration Status Accounting}

Configuration Status Accounting is the processing and recording of changes to the approved $A B$ baseline to maintain a continuous record of the TWRS AB. This includes for each of the documents that make up the $A B$. the revision level, current status, document owner, and information regarding changes (change traceability) and other data necessary for control and tracking, such as storage locations.

\subsection{Change Control}

A fundamental principle of configuration management is that a 17 changes must be accomplished by a systematic and measurable change process. The change control process assures that all potential changes are identified, evaluated, and controlled for the purposes of maintaining the TWRS $A B$ baseline. Applicable elements and functional requirements of change control include the following:

- Evaluation of Changes - Al1 proposals for temporary or permanent changes must be identified and evaluated to determine if an activity is within the existing TWRS AB. Changes will be classified (e.g., within $A B$, outside $A B$, or categorically excluded) to determine review and approval levels.

- Process Change as Amendment - Changes determined to be outside the existing TWRS $A B$ will be processed as an amendment to the existing TWRS AB. Amendments include additions, deletions, modifications to $A B$ documents such as the BIO and TSRs, or the development of new Justifications for Continued Operations. (JCOs) or other stand a) one $A B$ documents.

- Amendment Change Approval - Those changes determined to be outside the existing TWRS $A B$ will require RL review and approval. Processes will be established for the notification and scheduling of RL reviews. 




Figure 1 TWRS Authorization Basis Configuration Management Process 
- Implementation and Verification - Implementation plans establishing key interfaces for training, procedures, etc., may be developed for approved amendments depending on the complexity of the change. These implementation plans will be used as a map for the initial implementation of the change and will be integrated into a compliance matrix to be used to demonstrate compliance during normal operations and to maintain integrity of the TWRS $A B$. Verification of implementation will also be performed, including readiness reviews and physical verifications when needed.

- Periodic Updates - The TWRS AB must be maintained consistent with certain documents and the physical attributes of the facility. Periodic updates will provide for the improvement of the TWRS $A B$ through the incorporation of information not requiring $\mathrm{RL}$ approva1. The update process includes the contractor review and approval process as we 11 as a flowdown into the implementation process for incorporation of the change(s) consistent with that described for $A B$ amendments.

- Document Maintenance - Information will be made available to users by controlled means to assure that the information (paper and electronic copies) is. current and available. TWRS AB documents will be updated to reflect RL approved changes.

\subsection{Configuration Management Program Assessment}

Configuration Management requires periodic assessments to evaluate the adequacy, effectiveness and efficiency of the CM Program. Implementation of the assessment requirements are addressed in Section 4.5 .

\subsection{EXISTING CONTROLS AND PROCEDURES}

HNF-PRO-430, Safety Analysis Program is the integrating contractor procedure that outlines the requirements for the management of the $A B$. It establishes and interprets the safety analysis requirements and processes for the development and maintenance of the safety basis documentation for Project Hanford facilities based on applicable DOE Orders, Standards, and Policies as well as Hanford specific requirements.

The following sections describe the existing procedures and methods used to implement TWRS AB configuration management. This description follows the logic shown in Figure 1.

\subsection{Item Identification (Baseline Identification)}

The TWRS $A B$ includes the Basis for Interim Operation (BIO), its associated Technical Safety Requirements (TSRs), along with those additional $\mathrm{RL}$ approved documents and controls (Wagoner 1997) defined at the time the BIO was implemented. The approval of BIO, the TSRs, and other TWRS AB documents and their subsequent implementation (September 29, 1997) represents the establishment of the current TWRS $A B$ baseline. 
The current listing of the documents that make up the TWRS AB list are documented and maintained in. HNF-IP-0842, Volume IV, Section 5.4, Unreviewed Safety Question, Attachment A. Changes to this listing are based on RL direction and implemented by HNF-IP-0842, Volume I, Section 2.1, Procedure Development and Maintenance. Changes to the $A B$ baseline content are incorporated via Engineering Change Notices (ECNs) per WHC-IP-0842, Volume IV, Section 3.5, Engineering Documents.

\subsection{Configuration Status Accounting}

The configuration status accounting is achieved through Document Maintenance described in Section 4.3.5.

\subsection{Change Control}

The TWRS technical baseline change control process is currently under development and will be implemented via the TWRS CMIP when issued. This process will identify the CM requirements for the TWRS technical baseline.

This following section describes the existing controls and procedures used to implement change control for the TWRS AB.

\subsubsection{Evaluation of Change to $A B$}

Work process activities are screened for compliance to the TWRS AB by the USQ procedure, HNF-IP-0842, Volume IV, Section 5.4, Unreviewed Safety Questions. The USQ Process is used to screen potential change initiators and provides a graded, consistent, uniform review with respect to the $A B$. Per the USQ procedure, work activities that are evaluated and found to have a potential for being outside the existing $A B$ boundaries, require detailed evaluations to be performed, including reviews by the $\mathrm{P} 7$ ant Review Committee (PRC) when necessary. Changes to the $A B$ may be triggered when a proposed activity is determined to be outside of the existing $A B$. Change initiators include work process activities, revisions to procedures, design changes, modifications, reportable occurrences, Potential Inadequacies in the Authorization Bas is (PIABs), tests and experiments, new requirements, lessons learned, RL directed changes, and the revisions to documents outside the control of TWRS that may be relied on to implement safety basis requirements. Documents outside the control of TWRS include the Hanford Site Hoisting \& Rigging Manual and the Hanford Site Radiological Control Manual, as examples.

One outcome of the USQ Process is the conclusion that the activity, item, or situation is outside the existing $A B$ and requires an RL approved $A B$ amendment to proceed with the activity. The USQ process may also determine that the activity, item, or situation is within the existing $A B$; but an update to the $A B$ is required (e.g., editorials, items determined not to be a USQ and require a description change in TWRS $A B$ ). This type of change would be processed via a periodic update to the $A B$. These processes are discussed in the sections below. 


\subsubsection{Authorization Basis Amendment and Approval}

The procedure for development, review, approval, and implementation of amendments is summarized below.

HNF-IP-0842, Volume IV, Section 5.10, Authorization Basis Amendments and Annual Updates is the procedure used to process changes to the TWRS AB baseline. The roles and responsibilities for generation, review, approval, and implementation of TWRS authorization basis amendments and periodic updates are contained in this procedure. Review designations for FDH are contained in HNF-PR0-233, Review and Approval of Documents.

An $A B$ Amendment Package is the vehicle by which the TWRS AB baseline is modified to encompass projects and activities determined to be outside the existing $A B$ baseline. The preparation of this package may include $A B$ Amendment task planning, non-waste hazardous materials inventory/tank waste inventory updates, safety analysis preparation, safety analysis review, an Amendment Implementation $P 7 a n, A B$ document ECNs, and interfaces for contractor and RL review and approval. This package may also include approved JCOs for incorporation into the TWRS AB.

\subsubsection{Verification of Impiementation}

Facility compliance is defined in six program elements which include: a procedure compliance matrix for recording and tracking procedure compliance, an equipment matrix to record safety class and safety significant components, a training matrix to record safety related training for facility personnel, a quality assurance plan, the Unreviewed Safety Questions (USQ) process, and an $A B$ configuration management process.

Implementation of the TWRS $A B$ requirements and commitments and maintenance of facility compliance to the TWRS $A B$ is accomplished through the use of the procedure compliance matrix, the equipment matrix, and the training matrix, that identify safety basis requirements that are incorporated and implement Authorization Basis, compensatory measures (if any), and any approved amendments or revisions to the Authorization Basis documents as identified in Appendix A of the USQ procedure.

Facility compliance is evidenced within TWRS by the following:

- Authorization Basis Requirements Management Interface (ARMI) database which provides the traceability from $A B$ requirements to implementing procedures for specific facilities

- Safety Equipment List, HNF-WM-SD-SEL-040; and Tank Waste Remediation System Safety Structures, Systems, and Components: Requirements and Characteristics, WHC-SD-WM-RD-057, provide equipment and systems identification and documentation

- Quality Assurance P1an

- Training Information Management System (TIMS)

- Unreviewed Safety Question process outlined in HNF-IP-0842, Volume IV, Section 5.4 
These Administrative programs collectively ensure that the safety controls in the TWRS Authorization Basis documentation are implemented in TWRS.

\subsubsection{AB Update and Approval}

As referenced in Section 4.3.2, HNF-IP-0842, Volume IV, Section 5.10, Authorization Basis Amendments and Annual Updates is the procedure used to process changes to the TWRS $A B$ baseline, and details specific requirements for development, review, and approval of periodic updates.

The $A B$ Update process provides the means for incorporating approved changes and editorial improvements into the $A B$ documentation. Updates to the TWRS $A B$ occur periodically, at least annually. It is not a process for "upgrading" the $A B$. Approved changes include approved AB Amendments and Justifications for Continued Operation that have gone through the amendment process. The $A B$ Update process includes the collection of, physical updates, verifications, other editorial changes, and consolidation/integration of previously approved $A B$ documents (e.g., Operation Safety Requirements and other obsolete $A B$ documents).

\subsubsection{Document Maintenance}

Document maintenance ensures that the TWRS $A B$ documents are correct and available. Document maintenance encompasses how $R L$ approved $A B$ Amendments and Update changes will be incorporated into the $A B$ documents, how the electronic copies of the TWRS AB documents are to be updated and maintained, and controls the transmittal of information across organizational interfaces within the entire process.

Changes to the TWRS $A B$ documents are incorporated via the Engineering Change Notice (ECN) process outlined by WHC-IP-0842, Volume IV, Section 3.5 , Engineering Documents, and tracked by the site leve] Document Control System.

The $B I O$ and TSRs are the primary $A B$ documents defining the controls for the TWRS Facilities. These $A B$ documents are kept under controlled distribution. Changes generated via the ECN process for these documents are distributed in accordance with, HNF-PRO-225, Distributing Copy-Controlled Unclassified Documents. The remaining $A B$ documents (e.g., RL letters, Safety Evaluation Reports, etc.) are maintained as Non-Copy-Controlled Documents. These documents are distributed in accordance with HNF-PRO-228, Central Files and Distribution of Non-Copy-Controlled Documents.

TWRS NS\&L maintains individual sets of the $A B$ as record documents under direct custodial control. Field copies under direct custodial control are maintained in the following areas:

\footnotetext{
- 200 East Area Shift Office, TWRS Operations - Double Shel1 Tanks

- 200 West Area Shift Office, TWRS Operations - Single Shell Tanks

- TWRS Nuclear Safety \& Licensing Office

- TWRS Operations - Characterization Project Operations

- RL TWRS Safety \& Characterization Division office
} 
These field copies are designated as "Silver" copies. An additional set located in the Lockheed Martin Hanford Company Tank Characterization \& Safety Resource Library is the "Gold" copy and which is the master field copy. Bimonthly quality control checks are performed on these documents per desk instructions to ensure 1 atest changes have been incorporated. Latest changes are verified by review of. the site level Document Control System.

Electronic versions of the BIO and TSR documents are available for use via Procedure Information (PROC INF0). PROC INF0 provides the 1ink to the shared drive area where the controlled electronic files of the BIO/TSRs are maintained. Changes to the electronic version are coordinated through the TWRS NS\&L organization. The shared area is a "password-protected write area" and any updates to the electronic files are completed after ECN approval and issuance.

Databases and electronic information management system requirements for the control, maintenance, data verification, record, and archive will be addressed by the TWRS CMP and therefore are outside the scope of this document.

\subsection{Supporting Activities and Interfaces}

Al so identified during this evaluation were other activities that interface with the management and administration of the $A B$. These activities and items support the maintenance of the TWRS $A B$ but are not directly a part of the TWRS AB CM process, and therefore are not described in this document. Figure 1 identifies where these interfaces occur with respect to the TWRS AB process. These interfaces include:

- Emergency Preparedness

- Training Information Management Systems

- Quality Assurance PTan

- Safety Equipment List

- TWRS Health \& Safety PTan

- Operations Administrative Control Manual. (HNF-IP-1266)

- WHC-SD-WM-RD-057, TWRS Safety SSCs: Requirements \& Characteristics

- ARMI Database

- TWRS CMIP

- Integrated Safety Management System (ISMS)

These interfaces will ultimately be defined and managed via the TWRS CMP and ISMS. Changes to TWRS-owned procedures (HNF-IP-0842) that are relied upon by the TWRS $A B$ are required to go through the USQ process per HNF-IP-0842, Volume I, Section 2.1, Procedure Development and Maintenance. A Tisting of the HNF-IP-0842 procedures relied upon by the TWRS AB is provided in PROC INFO. Interim measures have been established to ensure that changes to documents outside TWRS control that are relied upon by the TWRS $A B$ are reviewed by NS\&L for impacts to the TWRS $A B$. This inciudes a revision to HNF-IP-0842, Volume IV, Section 5.6, Authorization Basis Facility Compliance Matrix, to provide a controlled list of documents outside of TWRS control (e.g., Hanford site-level procedures, DOE/RL. Hoisting \& Rigging Manual, Hanford Site Radiological Control Manual, etc.). The responsibility for evaluating changes to these documents for potential impacts to the $A B$ and updating the controlled list for approved revisions non-TWRS documents is also included in the revision to HNF-IP-0842, Volume IV, Section 5.6. 


\subsection{Configuration Management Program Assessments}

Assessments supporting configuration management are performed at several levels within TWRS, including both independent and internal assessments. The TWRS CMP will address and incorporate those existing (e.g., Facilities Evaluation Board, Management Observation Program) internal and external independent assessment systems and the specifics on protocols, schedules, plans, and corrective actions, etc. No additional independent assessments specific to the TWRS $A B$ are necessary.

\subsection{Management of Defense-in-Depth Features}

Defense-in-depth (DID) features include structures, systems, and components (SSCS) administrative and operations controls beyond those required by the TSRs. The DID structures, systems, components were not credited in the BIO accident analysis with prevention or mitigation of the accidents. Since credit was not taken in the analysis, they are not controlled at the same level as safety class/safety significant SSCS or TSRs. DID changes are made by ECNs that are approved by the contractor via standard engineering practices. The ECN process requires a USQ screen, therefore any changes will be reviewed against the TWRS $A B$. The changes are incorporated into the $A B$ as required during the periodic updates.

The TWRS Facility Safety Equipment List, HNF-SD-WM-SEL-040, is being updated to include a listing of the DID SSCs. Changes to this document wi11 be via the ECN process.

\subsection{CONCLUSION AND RECOMMENDATIONS}

This document was developed to identify the current $A B$ configuration management functional requirements, configuration control systems currently in place, and any additional measures that may be required to ensure maintenance of the TWRS $A B$ baseline.

This review concluded that the existing procedures and controls used for the management of the authorization basis are adequate and implemented and that the applicable elements of configuration management are in place for the effective management of the TWRS Authorization Basis.

In order to further assure this process is maintained the following recommendations are provided.

1. TWRS Configuration Management Plan is currently in revision. The TWRS CMP, once issued, should be reviewed to ensure the $C M$ requirements with respect to the TWRS $A B$ are met and that the TWRS $A B C M$ process is transitioned under the overal1 TWRS CM P1an.

Recommendation 1: Reconcile the TWRS AB CM process identified in this document with respect to the TWRS CMP. Ensure that the interface requirements and controls are established in the TWRS CMP for the following:

- Electronic databases

- Configuration Management Assessments 
2. RL directed changes are one mechanism that initiates change to the TWRS $A B$ documentation. The process used to evaluate and implement the directed change is not formally defined.

Recommendation 2: Formally define the RL Directed Change Process to:

- $\quad$ Determine interface with FDH on the RL directed changes (HNF-PRO107)

- Determine how RL direction with respect to changes to the TWRS AB is received and how it is integrated into the TWRS $A B$ CM process

- Establish a mechanism to track all RL directed changes to the TWRS $\mathrm{AB}$

3. Some of the procedures listed in Table 1 are relied upon by TWRS NS\&L to implement portions of the TWRS AB Configuration Management process. Many of these procedures are not owned by. TWRS NS\&L.

Recommendation 3: Interface agreements/mechanisms must be formalized with the owners of these documents to ensure that proposed changes to these documents are evaluated with respect to the TWRS $A B$. It is intended that this will be included in the TWRS technical baseline change control process when finalized.

4. Some documents relied upon by the TWRS AB (e.g., Hanford site-level procedures, Hoisting \& Rigging Manual, Hanford Site Radiological Control Manual, etc.) are outside of TWRS control.

Recommendation 4: Interface agreements/mechanisms must be formalized with the owners of these documents to ensure that proposed changes to these documents are evaluated (USQ Process) with respect to the TWRS AB. These interfaces will ultimately be defined and managed via the TWRS CMP and ISMS.

5. Procedures direct7y owned by TWRS NS\&L which implement the TWRS AB CM processes are listed below:

- Plant Review Committee, HNF-IP-0842, Vol IV, Section 5.1

- Unreviewed Safety Question, HNF-IP-0842, Vol IV, Section 5.4

- Facility Compliance Matrix, HNF-IP-0842, Vol IV, Section 5.6

- Authorization Basis Amendments and Annual Updates, HNF-IP-0842, Vol IV, Section 5.10

Recommendation 5: Procedures listed above directly owned by TWRS NS\&L will be addressed for process improvement and updated to reflect current organizational structures and more clearly present the requirements for TWRS $A B$ configuration management.

6. Training on the TWRS AB CM process that has been identified by this document is needed to ensure personnel (e.g., engineering and operations) are made aware of this process and the implementing procedures.

Recommendation 6: Identify personnel and establish methods (e.g., shift meetings, PRC, etc.) for training personnel with respect to the TWRS AB $C M$ process and the procedures and controls that implement the process. 
Table 1 - Topical Section References \& Implementing Procedures

\begin{tabular}{|c|c|c|c|}
\hline Section & subject & Procedure Document Number & Title of Procedure \\
\hline \multirow[t]{5}{*}{1.0} & Authorization Basis (AB) & HNF-SD-WM-BIO-001, ReV 0 & TWRS Basis for Interim Operation (BIO) \\
\hline & Technical Safety Reqmts. (TSR) & HNF-SD-WM-TSR-006, ReV 0 & TWRS Technical safety Requirements \\
\hline & Configuration Management Plan & HNF-SD-WM-CM-013 & TWRS Configuration Management Plan \\
\hline & Config. Mgmt. Imp. Plan (CMIP) & $H N F-S D-W M-C M-014$ & TWRS CM Implementation Plan \\
\hline & Configuration Management & HNF-MP-013 & Configuration Management Plan \\
\hline 1.1 & DOE/RL Mgmt. Assessment & DOE/RL-97-72, Rev 0, Mgmt Assessment & Readiness to Implement TWRS Basis for Interim Operations \\
\hline \multirow[t]{2}{*}{2.0} & Configuration Management & HNF-MP- 013 & Conf iguration Management Plan \\
\hline & & HNF-SD-WM-CM-014 & TWRS CM Program Implementation Plan \\
\hline 2.1 & RL Docket & TWRS- XXX (draft in development) & Management of the TWRS Authorization Basis \\
\hline 2.3 & Organizational Charter & HNF-IP-0842, Vol 1 , Section 3.30 & TWRS Engineering and Nuclear Safety Charter \\
\hline 2.4 & organizational charter & HNF-IP-0842, Vol I, Section 3.30 & TWRS Engineering and Nuclear Safety Charter \\
\hline 2.5 & Plant Review Committee & HNF-IP-0842, Vol IV, Section 5.1 & Plant Review Committee \\
\hline \multirow[t]{2}{*}{3.0} & Configuration Management & HNF-MP-013 & Configuration Management Plan \\
\hline & Safety Basis & HNF-PRO-430 & Safety Analysis Program \\
\hline \multirow[t]{5}{*}{4.1} & Basel ine Management & HNF-PRO- 430 & Safety Analysis Program \\
\hline & Basel ine Documentation & HNF-IP-0842 Vol IV, section 5.4 & Unreviewed Safety Question, Attachment A \\
\hline & Document Change & HNF-IP-0842, Vol I, Section 2.1 & Procedure Development and Maintenance \\
\hline & Eng. Change Notice & HNF-PRO- 440 & Engineering Document Change Control Process \\
\hline & & WHC-IP-0842, Vol IV, Section 3.5 & Engineering Documents \\
\hline \multirow[t]{2}{*}{4.3 .1} & Change Identification & HNF-IP-0842, Vol IV, Section 5.4 & Unreviewed Safety Question \\
\hline & AB Amendment \& Update & HNF-IP-0842, Vol IV, Section 5.10 & Authorization Basis Amendments and Annual Updates \\
\hline \multirow[t]{3}{*}{4.3 .2} & AB Amendment \& Update & HNF-IP-0842, Vol IV, Section 5.10 & Authorization Basis Amendments and Annual Updates \\
\hline & Amendment Imp: Plan & HNF-IP-0842, Vol IV, Section 5.10 & Authorization Basis Amendments and Annual Updates \\
\hline & . & HNF-PRO-233 & Review. and Approval of Documents \\
\hline 4.3 .3 & Eng. Change Notice & HNF-PRO-440 & Engineering Document Change Control Process \\
\hline
\end{tabular}




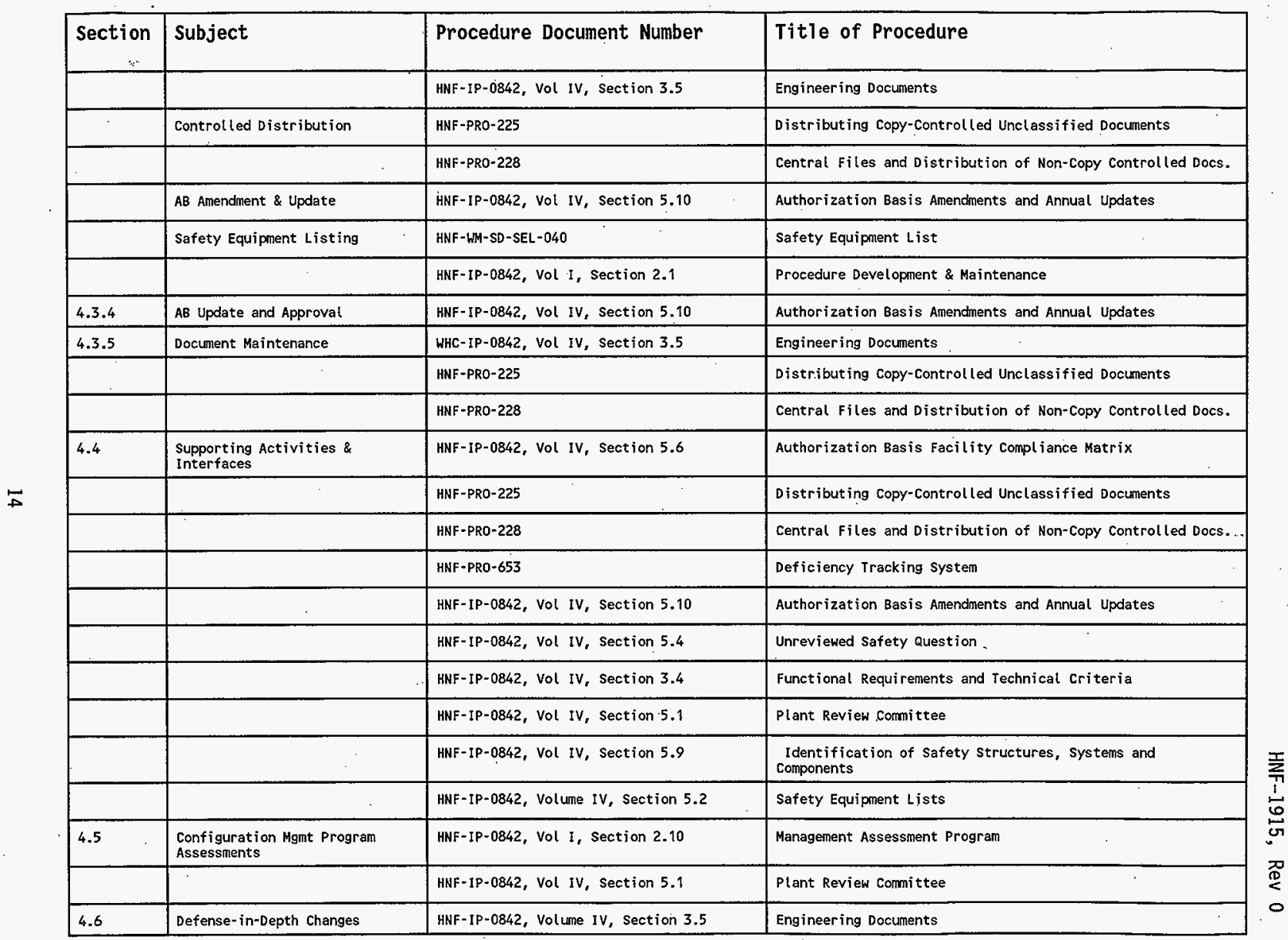




\subsection{REFERENCES}

DOE Documents:

DOE/RL-97-72, Rev. 0, U.S. Department of Energy, Richland Operations Office, Tank Waste Remediation System Management Assessment - Volume I, Determination of Readiness to Implement Tank Waste Remediation Basis for Interim Operations

DOE-STD-1073-93, Guide for Operational Configuration Management

Letter, J. D. Wagoner, RL, to H. J. Hatch, FDH, Contract Number DE-ACO696RL13200 - Approval of Tank Waste Remediation System (TWRS) Basis for Interim Operation (BIO) Readiness and Revised Authorization Basis, 97SCD-024, dated September 12, 1997

Fluor Daniel Hanford Documents:

HNF-MP-013, Configuration Management Plan

HNF-PR0-107, Responding to RL Direction

HNF-PRO-225, Distributing Copy-Controlled Unclassified Documents

HNF-PRO-228, Central Files and Distribution of Non-Copy-Controlled Documents

HNF-PRO-233, Review and Approval of Documents

HNF-PR0-430, Safety Ana7ysis Program

HNF-PR0-440, Engineering Document Change Control Requirements

HNF-PR0-653, Deficiency Tracking System

HNF-PR0-705, Safety Basis P7anning, Documentation, Review and Approval

TWRS Documents:

HNF-SD-WM-CM-013, TWRS CM Program P7an

HNF-SD-WM-CM-014, TWRS CM Program Implementation Plan (CMIP)

HNF-IP-0842, Volume I, Section 2.1, Procedure Development and Maintenance

HNF-IP-0842, Volume I, Section 2.10, Management Assessment Program

HNF-IP-0842, Volume I, Section 3.30, TWRS Engineering \& Nuclear Safety Charter

WHC-IP-0842, Volume IV, Section 3.4, Functional Requirements and Technical Criteria

WHC-IP-0842, Volume IV, Section 3.5, Engineering Documents

HNF-IP-0842, Volume IV, Section 5.1, Plant. Review Committee 
WHC-IP-0842, Volume IV, Section 5.2, Safety Equipment Lists

HNF-IP-0842, Volume IV, Section 5.4, Unreviewed Safety Questions

HNF-IP-0842, Volume IV, Section 5.6, Authorization Basis Facility Compliance Matrix

WHC-IP-0842, Volume IV, Section 5.9, Identification of Safety Structures, Systems, and Components

WHC-IP-0842, Vol IV, Section 5.10, Authorization Basis Amendments and Annual Updates

HNF-SD-WM-SEL-040, Rev. 0, TWRS Faci7ity Safety Equipment List

HNF-SD-WM-BI0-001, Rev. OD, Tank Waste Remediation System Basis for Interim Operation

HNF-SD-WM-TSR-006, Rev. OE, Tank Waste Remediation System Technica7 Safety Requirements

WHC-SD-WM-RD-057, Rev. 0B, Tank Waste Remediation System Safety Structures, Systems, and Components: Requirements and Characteristics 


\subsection{DEFINITIONS}

The following terms are used in this document. The definitions and sources are:

Authorization Basis (AB) - Documents describing aspects of the facility design basis and operational requirements relied upon by DOE to authorize operation. These aspects are considered to be important to the safety of facility operations. The authorization basis is described in documents such as the facility safety analysis report and other safety analyses, hazard classification documents, the technical safety requirements, DOE-issued safety evaluation reports, and facilityspecific commitments made to comply with DOE orders or policies. (HNFIP-0842, Vol IV, Section 5.8 Development and control of TWRS Safety Bases.)

(Characteristics of authorization basis documents are: 1) they are that portion of the safety basis approved by DOE as authorization basis documents; or 2) they are DOE prepared documents, either documents identified by DOE to be in the authorization basis or a DOE safety evaluation report (HNF-IP-0842, Volume IV, Section 2.3).)

Baseline - The original plan (for a project, a work package, or an activity), plus or minus approved changes. Usually used with a modifier, e.g., cost baseline, schedule baseline, performance measurement baseline, etc.) (Configuration Management Plan, HNF-MP-013)

Configuration Control - The process of controlling changes to a configuration and of statusing that configuration. (HNF-MP-013, PHMC Configuration Management Plan)

Configuration Management $(\mathrm{CM})$ - An integrated management program used to estabijsh consistency among requirements, basis, functional configuration, and documentation, and maintains this consistency throughout the 1 ife of the product as the changes occur. (Configuration Management Requirements Source Document HNF-SD-WM-CM-016)

"The systematic evaluation, coordination, approval (or disapproval), documentation, implementation, and audit of all approved changes in the configuration of a product after forma 7 establishment of its configuration identification" (DOE 5480.23, Nuclear Safety Analysis Reports)

Configuration Management Controls - The management controls and systems put in place to implement a configuration management program.

Defense-In-Depth (DID) - Engineered features and administrative programs and procedures that act to further prevent or mitigate accident risk beyond the safety structures, systems, and components and Technical Safety Requirement controls are identified as defense-in-depth controls. Defense-in-depth controls that provide for significant risk reduction were elevated to safety structures, systems, and components or Technical Safety Requirement controls. Al though defense-in-depth items are not controlled as safety structures, systems, and components or Technical Safety Requirement controls, they add to overall safety and are governed 
by configuration control procedures. Identification in the defense-indepth controls increases the awareness of the contribution these features make to safety. (HNF-SD-WM-BI0-001 - TWRS Basis for Interim operation)

Plant Review Committee (PRC) - A committee made up of senior managers trained in the Unreviewed Safety Question process who assist the Vice President, Tank Waste Operations, in making decisions concerning identification and resolution of unreviewed safety questions (USQS) and other matters relating to the safe operation of the tank farm facility. (Plant-Review Committee, HNF-IP-0842, Volume IV, Section 5.1)

Technical Safety Requirements (TSR) - Those requirements that define the conditions, safe boundaries, and the management or administrative controls necessary to ensure the safe operation of a facility and to reduce the potential risk to the public and facility workers from uncontrolled releases of nonradioactive material, radioactive materials, or from radiation exposures due to inadvertent criticality. Technical safety requirements consist of safety limits, operating limits, surveillance requirements, administrative controls, use and application instructions, and the basis thereof. Technical safety requirements were formerly known as operational safety requirements for non-reactor nuclear facilities and technical specifications for reactor facilities (DOE 5480.22).

Unreviewed Safety Question (USQ) - An unreviewed safety question exists if any of the following circumstances hold:
a. If the frequency of occurrence or the consequence of an accident or malfunction of equipment important to safety previously evaluated in the authorization basis could be significantly increased.
b. If the possibility for an accident or malfunction of equipment of a difference type than any evaluated previously in the authorization basis could be created.
c. If any margin of safety, as defined in the bases for any transitional requirements (Operation Safety Requirements, Interim Operational Safety Requirements) and Technical Safety Requirement (TSR) could be reduced.

\section{(HNF-IP-0842, Volume IV, Section 5.4 Unreviewed Safety Question)}

USQ Process (as used in this document) - The overall process used to determine if an unreviewed safety question exists and to obtain DOE authorization for continued operation. This process includes the screening of potential USQ initiating documents, USQ determinations, notifications to DOE, revision to the authorization basis by amendment, implementation plans, and the DOE approval/authorization. 
DISTRIBUTION SHEET

\begin{tabular}{|c|c|c|c|c|c|}
\hline \multirow{2}{*}{$\begin{array}{l}\text { To } \\
\text { Distribution }\end{array}$} & \multirow{2}{*}{\multicolumn{3}{|c|}{$\begin{array}{l}\text { From } \\
\text { D. P. Mendoza }\end{array}$}} & \multicolumn{2}{|l|}{ Page 1 of 1} \\
\hline & & & & \multicolumn{2}{|c|}{ Date $12 / 19 / 97$} \\
\hline \multicolumn{4}{|c|}{ Project Title/Work Order } & \multicolumn{2}{|c|}{ EDT No. 623766} \\
\hline \multicolumn{4}{|c|}{$\begin{array}{l}\text { Integrated Transition List of Items and Conditions - Action Item } \\
\# 18 \mathrm{~A} \text {, Authorization Basis Configuration Management }\end{array}$} & \multicolumn{2}{|c|}{ ECN No. $\quad N / A$} \\
\hline \multicolumn{2}{|c|}{ Name } & $\begin{array}{l}\text { Text } \\
\text { With All } \\
\text { Attach. }\end{array}$ & Text Only & $\begin{array}{l}\text { Attach./ } \\
\text { Appendix } \\
\text { Only }\end{array}$ & $\begin{array}{l}\text { EDT/ECN } \\
\text { Only }\end{array}$ \\
\hline
\end{tabular}

\section{J. J. Badden}

D. G. Baide

R. M. Boger

M. C. Brady

C. B. Bryan

R. J. Cash

J. S. Davis

E. P. DiVincenzo

R. A. Dodd

G. W. Gault

T. C. Geer

E. R. Hamm

J. L. Homan

T. J. Kelley

C. E. Leach

D. P. Mendoza

R. S. Popielarczyk

J. G. Propson

R. E. Raymond

S. H. Rifaey

$\begin{array}{ll}\text { T4 }-07 & X \\ \text { S5-05 } & X \\ \text { S7-12 } & X \\ \text { R1-43 } & X \\ \text { T4-07 } & X \\ \text { S7-14 } & X \\ \text { R1-49 } & X \\ \text { R2-54 } & X \\ \text { S5-07 } & X \\ \text { R1-44 } & X \\ \text { R1-43 } & X \\ \text { R1-30 } & X \\ \text { T4-07 } & X \\ \text { S5-07 } & X \\ \text { R1-49 } & X \\ \text { R1-43 } & X \\ \text { S7-01 } & X \\ \text { R1-43 } & X \\ \text { R2-38 } & X \\ \text { R1-56 } & X \\ S 7-84 & X\end{array}$

